Article

\title{
Fostering Awareness on Environmentally Sustainable Technological Solutions for the Post-Harvest Food Supply Chain
}

\author{
Carlos M. Fernandez ${ }^{1}$, Joel Alves ${ }^{1}$, Pedro Dinis Gaspar ${ }^{1,2, * \mathbb{D}}$ and Tânia M. Lima ${ }^{1,2}$ (D) \\ 1 Department of Electromechanical Engineering, University of Beira Interior, Rua Marquês de D'Ávila e \\ Bolama, 6201-001 Covilhã, Portugal; carlos.fernandez@ubi.pt (C.M.F.); joel.alves@ubi.pt (J.A.); \\ tmlima@ubi.pt (T.M.L.) \\ 2 C-MAST-Center for Mechanical and Aerospace Science and Technologies, Rua Marquês de D'Ávila e \\ Bolama, 6201-001 Covilhã, Portugal \\ * Correspondence: dinis@ubi.pt
}

Citation: Fernandez, C.M.; Alves, J.; Gaspar, P.D.; Lima, T.M. Fostering Awareness on Environmentally Sustainable Technological Solutions for the Post-Harvest Food Supply Chain. Processes 2021, 9, 1611. https://doi.org/10.3390/pr9091611

Academic Editors: Tiane Finimundy, Taofiq Oludemi and Filipa S. Reis

Received: 5 August 2021

Accepted: 6 September 2021

Published: 8 September 2021

Publisher's Note: MDPI stays neutral with regard to jurisdictional claims in published maps and institutional affiliations.

Copyright: (c) 2021 by the authors. Licensee MDPI, Basel, Switzerland. This article is an open access article distributed under the terms and conditions of the Creative Commons Attribution (CC BY) license (https:// creativecommons.org/licenses/by/ $4.0 /)$.

\begin{abstract}
This study presents a current status and future trends of innovative and environmentally sustainable technological solutions for the post-harvest food supply chain and the food industry, in terms of ecological packaging, active, and/or intelligent packaging. All these concerns are currently highlighted due to the strong increase in the purchase/sale of products on online platforms, as well as the requirements for stricter food security and safety. Thus, this study aims to increase the global awareness of agro-industrial micro, small, and medium size enterprises for the adoption of innovative food solutions though industry digitalization (Industry 4.0), associated logistics and circular economy, with a concern for cybersecurity and products information, communication and shelf-life extension. The adoption of these guidelines will certainly foster along the complete food chain (from producer to consumer, with all intermediary parties) the awareness on environmentally sustainable technological solutions for the post-harvest food supply chain, and thus, promoting the future food sustainability required by the population increase, the climate change, the exodus of rural population to urban areas, and food loss and waste.
\end{abstract}

Keywords: agro-industry; food supply chain; sustainability; packaging; food safety; circular economy; industry 4.0 and cybersecurity; waste

\section{Introduction}

New consumption patterns were developed and trade barriers were reduced due to globalization [1]. Online commerce is growing abruptly in developed countries, with an increase from $32 \%$ in 2015, with 20 billion orders, to $43 \%$ in 2018 . It is also expected to grow an additional $26 \%$ by 2026 [2]. In addition, the emergence of sensors and low-cost information technologies, as well as business analysis tools, have changed the majority of agro-food supply chains and the agro-industrial sector [1]. This change to a "disposable society" has put a high pressure on the planet's raw materials and resources [3].

The dominant economic development model is based on "take, make and disposal", unfortunately leading to unsustainable growth [4]. The current context is revealed by the global material footprint as an indicator of the pressure on the environment to support economic growth to satisfy the material needs of people, such as food, clothing, water, shelter, infrastructures and other aspects of living. In 2010, the global material footprint was 73.2 billion of metric tons and seven years after, in 2017, it grew by $17.4 \%$ to 85.9 billion metric tons. The electronic and electrical equipment disposal is growing fast, driven by a huge consumption, short product life cycle, and limited repair. Consequently, the recycling process is slower than the waste production. While waste grew annually worldwide from 5.3 to $7.3 \mathrm{~kg}$ per capita from 2010 to 2019 , recycling grew annually from 0.8 to $1.3 \mathrm{~kg}$ per capita [5]. 
So, sustainability is a broad concept that addresses most aspects of the human life, playing an important role in the social, environmental, and economic aspects. According to the Brundtland Report [6], also known as Our Common Future, sponsored by the United Nations (UN), it is a movement to ensure a better and more sustainable well-being for all, including future generations. It aims to address global issues such as injustice, inequality, peace, climate change, pollution, and environmental degradation [7]. Sustainable consumption and production can only be achieved if natural resources are used in a responsible manner, which is highlighted by the UN in the 12th goal of the sustainable development report [5]. In addition, one of the sustainable development goals is to halve the food waste per capita in food retail and by consumers by 2030. To accomplish this objective it is crucial to reduce food waste throughout the food supply chain (FSC) and production [8].

A significant contribution against the sustainability is caused by food loss and waste (FLW) along the FSC. According to the UN, the proportion of food loss and waste after harvesting and during transport, storage and processing is $13.8 \%$, summarizing over $\$ 400$ billion a year. This scenario could be even worse, raising up to $20 \%$ if retail and distribution and final consumption in households and food services is included [9]. It is also estimated that $1 / 3$ of the food produced is wasted. It is important to notice that food waste is unequivocally linked to food security and resource management [8].

Some form of action is imperative to decrease mankind's reliance on raw materials and change to a circular economy approach aiming at "recycling, reuse or recovery" to reduce environmental pressure and impact $[4,5,10-13]$. The European Union's (EU) goal is to reduce greenhouse gas emissions by at least $40 \%$ when compared to 1990 , increase up to $32 \%$ in the share of renewable energy and up to $32.5 \%$ improvement in energy efficiency [14]. This is due to the fact that $80 \%$ of the energy produced in the world comes from fossil fuels, which requires a gradual adjustment to a more sustainable, accessible, and secure global energy system [15]. The agro-food sector has a significant impact on the world's sustainability and it is responsible for $20 \%$ of global land, $70 \%$ percent of water, and $32 \%$ of total energy consumption and during the productive process, generates solid waste, greenhouse gas emissions, and other pollutants. Most agro-food industry use refrigeration to refrigerate food products [16]. A cold environment is required to ensure the maintenance of the organoleptic characteristics of perishable food products and extend food quality and safety. Some examples are provided by Andrade et al. and Rodrigues et al. [17,18]. Electrical energy is consumed continuously to power these systems. Energy efficiency measures are also required to improve the sustainability of the sector [19,20]. Additionally, it must be taken into account that refrigerants used in these systems have a relevant environmental impact. An international effort, technological and political, has been developed to foster the use of low environmental impact refrigerants [21]. In the last few years in the EU, this trade was valued of 254 billion euros in 2018-138 billions of exports and 116 billion of imports [22]. Almost 44 million jobs in the EU are provided by agriculture and food related industries and services together, including regular work for 22 million people within the agricultural sector itself. The food production and processing chain accounts for $7.5 \%$ of employment in the EU.

It is not about food waste itself, but the complete supply chain of waste of limited resources such as soil, water, fertilizers, human labor, oil, $\mathrm{CO}_{2}$ emissions, and electricity, among others. On the other hand, losses reduction brings cost reduction, less emissions, optimized consumption of resources, among other benefits [9], or in other words, increased eco-efficiency [23]. The main questions raised by this study are "What are the sustainability challenges in the agro-industrial business? How can packaging contribute to sustainability in this sector?". Therefore, this work intends to discuss the trends for the sustainability of the agro-industrial sector, from the adoption of the most recent technologies that can increase efficiency, namely ecological, active, and intelligent packaging. Additionally, it draws attention to food waste throughout the FSC, which is a key factor to achieve sustainability and at the same time improve efficiency and reducing costs and greenhouse gas emissions. 
This study presents the current status and future trends review of innovative and sustainable technological solutions for the agro-industrial sector, in terms of circular economy, ecological packaging, active and/or intelligent packaging and associated logistics, and industry digitalization (cybersecurity and products information and communication). The schematic diagram of sustainability based on circular economy strategies shown in Figure 1 was elaborated to represent these interconnected areas of the agro-industrial sector. In addition, it is necessary to adopt the new Digitalization Era with Industry 4.0 technologies and cybersecurity, and, simultaneously, applying a circular economy strategy. To perform this, closed loops in the whole food supply chain are required, through biosphere regeneration and renewable materials and by introducing the losses, waste management, and new systems of packaging such as active and/or intelligent, reusable, or recyclable packaging.

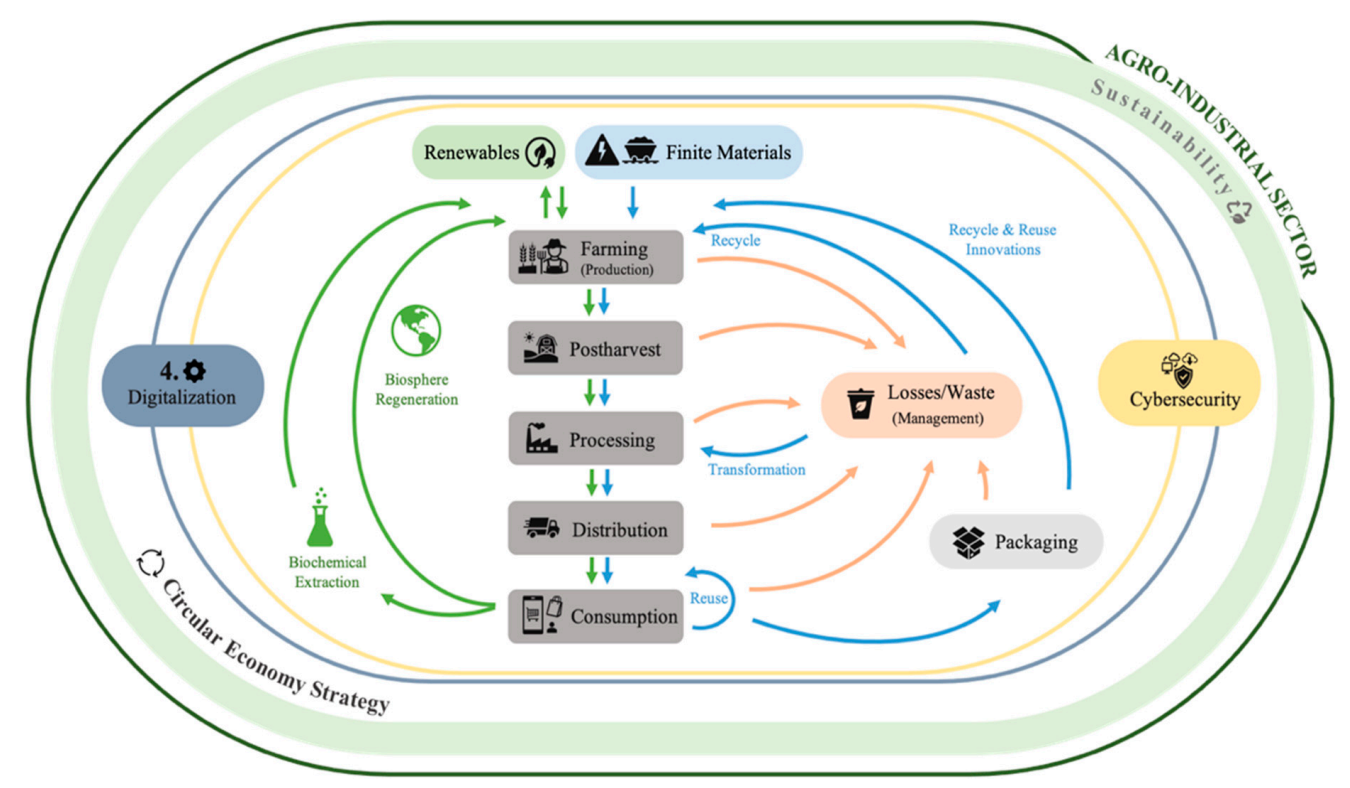

Figure 1. Schematic representation of the agro-industrial sector and its interconnected areas.

\section{Materials and Methods}

A bibliographic review was performed to answer the main questions of the study. Scientific papers published in the last five years composed this bibliographic review. The main databases used in the research were from internationally trusted publisherindependent databases such as Web of Science and Scopus, as well as publishers' databases, particularly, Elsevier (Science Direct) and MDPI. It should be noted that some articles and websites additional to this research were also used to supplement the information pertinent to this document. In addition, government, institutional reports, and white papers were also included.

The main objective to answer the main question is to relate sustainability in the agroindustrial sector through food packaging, ecological, intelligent, active, circular economy, or even industry 4.0. The search keywords were applied in title, abstract, and keyword, as follows:

TITLE-ABS-KEY (("agro-industry" AND ("food packaging”) OR "ecological packaging" OR ("Intelligent Packaging") OR ("Active Packaging") OR ("Circular Economy") OR ("Industry 4.0") OR “Cybersecurity" OR “Loss and Waste")).

The selection criteria listed below are defined according to the contents of interest:

(1) Identification and characterization of waste sources in agro-industrial micro, small and medium enterprises (MSMEs) and to develop innovative solutions that engage waste or subproducts reduction or reuse, to improve productive efficiency and reduce environmental impacts, in a circular economy strategy; 
(2) Enable MSMEs to be more efficient and innovative through access to training processes for the introduction of scientific and technological innovation in the product and process development and in their value chain and to accelerate the adoption of Industry 4.0, linked to sustainability and preservation of ecosystems (eco-design of processes and products, eco-efficiency and digital economy);

(3) Practices in cybersecurity, i.e., in the use of technologies both at software level and at the operator level, to increase the confidence of companies to adopt Industry 4.0 technologies and the use of digital environments;

(4) Practices in the use of sustainable (ecological) primary packaging to prepare companies to comply with future regulations arising from the environmental impact;

(5) Practices in the use of sustainable secondary packaging (recyclable and/or reusable);

(6) Practices in intelligent and/or active packaging to increase their market penetration in order to help reduce food waste and improve food safety;

(7) Only papers written in English were included;

(8) Subjects other than those mentioned above or duplicated papers were excluded.

After the selection criteria, 45 papers were chosen and 14 references were included to complement the research.

\section{Food Loss and Waste in Agro-Industrial Sector}

Food waste is an environmental, economic, and social issue. The reduction of this waste is a way of reducing production costs, increasing the efficiency of the food system, improving food and nutritional security, and contributing to an environmentally sustainable food system [24]. Food loss refers to food that is intended for human consumption but, due to inefficiencies in FSC is reduced in quantity or quality. Food waste refers to food for human consumption that is discarded, both edible and inedible parts, due to intentional behaviors [25]. Food loss is generally related to primary production, postharvest, processing, transport, storage, and packaging (upstream) while food waste is related to wholesale, retail, food services, and households (downstream) [26]. Table 1 describes the causes of food losses and wastes in different FSC stages. In general, and across all stages, the main causes of FLW in the agro-industrial sector are related to logistic and management problems, improper food handling, and also consumer choices and mindsets.

In order to contribute with the best practices for a more sustainable sector, the agroindustry must reuse and recycle FLW. Thus, clean technologies must be applied to reduce the environmental impact and minimize the organic waste through recycling, as shown in Figure 2 [27]. These recycling strategies allows the transformation of "Agro-Wastes" in diverse components and compounds that may be used in this or another's sectors.

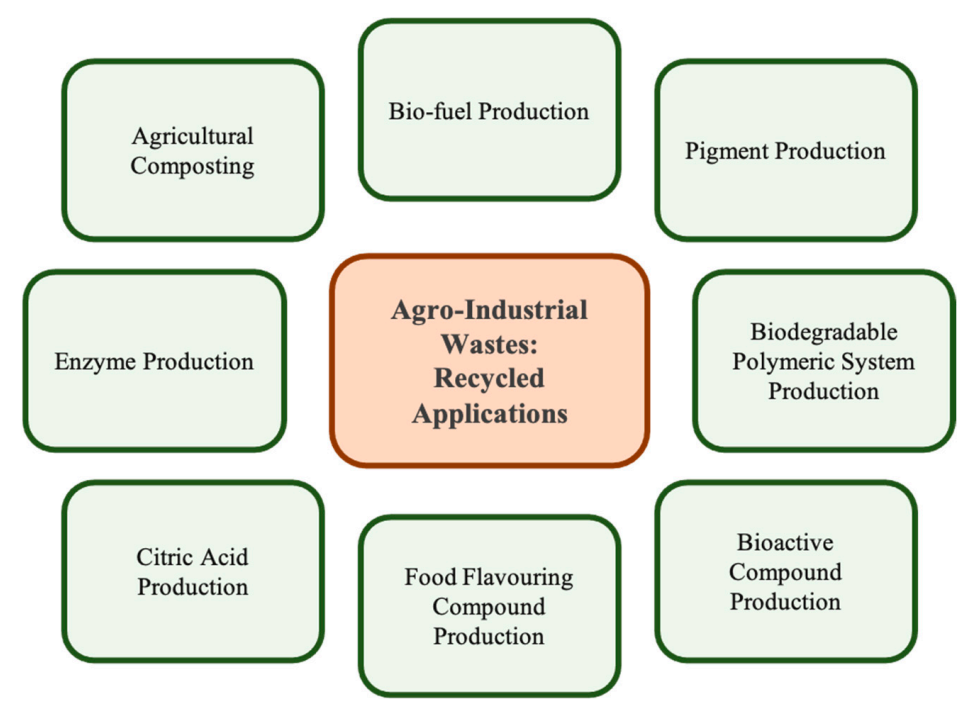

Figure 2. Diverse applications of recycled agro-industrial wastes (adapted from [27]). 
Table 1. Causes of food loss and waste (FLW) throughout the food supply chain (FSC) (adapted from [25]).

\begin{tabular}{|c|c|c|}
\hline (1) Postharvest & (3) Distribution & (5) Food Service \\
\hline $\begin{array}{l}\text { Grading standards for size and quality; } \\
\text { Inaccurate supply-and demand } \\
\text { forecasting; } \\
\text { Order cancellations; } \\
\text { Employee behavior; } \\
\text { Low market prices and lack of markets } \\
\text { (especially for second grade products); } \\
\text { Inadequate sorting; } \\
\text { Damage from handling; } \\
\text { Spoilage and degradation; } \\
\text { Inappropriate transportation and storage } \\
\text { conditions; } \\
\text { Cold-chain (refrigeration during } \\
\text { transportation and storage) deficiencies; } \\
\text { Labor shortages. }\end{array}$ & $\begin{array}{l}\text { Damage during transport; } \\
\text { Inaccurate supply and demand } \\
\text { forecasting; } \\
\text { Cold-chain deficiencies; } \\
\text { Rejection of shipments; } \\
\text { Poor record keeping; } \\
\text { Inappropriate transportation and storage } \\
\text { conditions; } \\
\text { Incorrect/ineffective packaging; } \\
\text { Delays during border inspections; } \\
\text { Road infrastructure challenges; } \\
\text { Excessive food distribution } \\
\text { centralization. }\end{array}$ & $\begin{array}{l}\text { Plate composition; } \\
\text { Expansive menu options; } \\
\text { Over-serving and over-preparing; } \\
\text { Unexpected demand fluctuations; } \\
\text { Preparation mistakes; } \\
\text { Improper handling and storage; } \\
\text { Rigid management; } \\
\text { Facility employee behavior; } \\
\text { Food safety concerns; } \\
\text { Use of trays; } \\
\text { Marketing practices. }\end{array}$ \\
\hline (2) Processing & (4) Retail & \\
\hline $\begin{array}{l}\text { Inadequate infrastructure and machinery; } \\
\text { Inefficient system designs; } \\
\text { Damage during production; } \\
\text { Inaccurate supply-and demand } \\
\text { forecasting; } \\
\text { Contamination; } \\
\text { Trimming and culling; } \\
\text { Supply/demand issues; } \\
\text { Inconsistent/confusing date labels; } \\
\text { Inconsistency in quality of ingredients; } \\
\text { Food safety issues; } \\
\text { Production line changes; } \\
\text { Cold-chain deficiencies; } \\
\text { Facility employee behavior. }\end{array}$ & $\begin{array}{l}\text { Inaccurate supply and demand } \\
\text { forecasting; } \\
\text { Overstocking; } \\
\text { Food safety concerns; } \\
\text { Inconsistent/confusing date labels; } \\
\text { Order minimums and fluctuations in } \\
\text { delivery from suppliers; } \\
\text { Cold-chain deficiencies; } \\
\text { Rejection of shipments; } \\
\text { Increasing merchandising standards; } \\
\text { Product differentiation; } \\
\text { Market over-saturation; } \\
\text { Rigid management; } \\
\text { Marketing practices. }\end{array}$ & \\
\hline
\end{tabular}

\section{Logistics: Product and Process Development}

The imminent environmental, political, and cultural crisis requires that society, governments, companies, manufacturers, and resource users adopt a more sustainable approach that is not dependent on scarce resources with volatile prices [13]. Thus, the world must increase the efficiency of natural resources use and reduce the environmental impact. This increase in resource efficiency is fundamental to the transition to a circular economy and to the reduction of FLW, in order to achieve a sustainable balance [28].

Through the analysis of the diagram of sustainability in the agro-industry, shown in Figure 3, it is possible to verify that the FSC is composed by farming (production), postharvest, processing, distribution, and consumption, and their different goals should be taken in consideration through the circular economy and FLW reduction [29,30]. The political and cultural aspects must be considered in addition to the three pillars of a sustainability society, the environment, and the economy in the agri-food sector. Increased packaging and logistics efficiency can bring eco-efficiency in the agro-industry, as well as applying solutions as eco-design in primary and secondary packaging, the adoption of active and/or intelligent packaging [31], the use of differentiated packaging to improve logistics, the adoption of Internet of Things (IoT) and algorithms to improve efficiency, the use extended traceability [32], and cold chain logistics [33] approaches. 


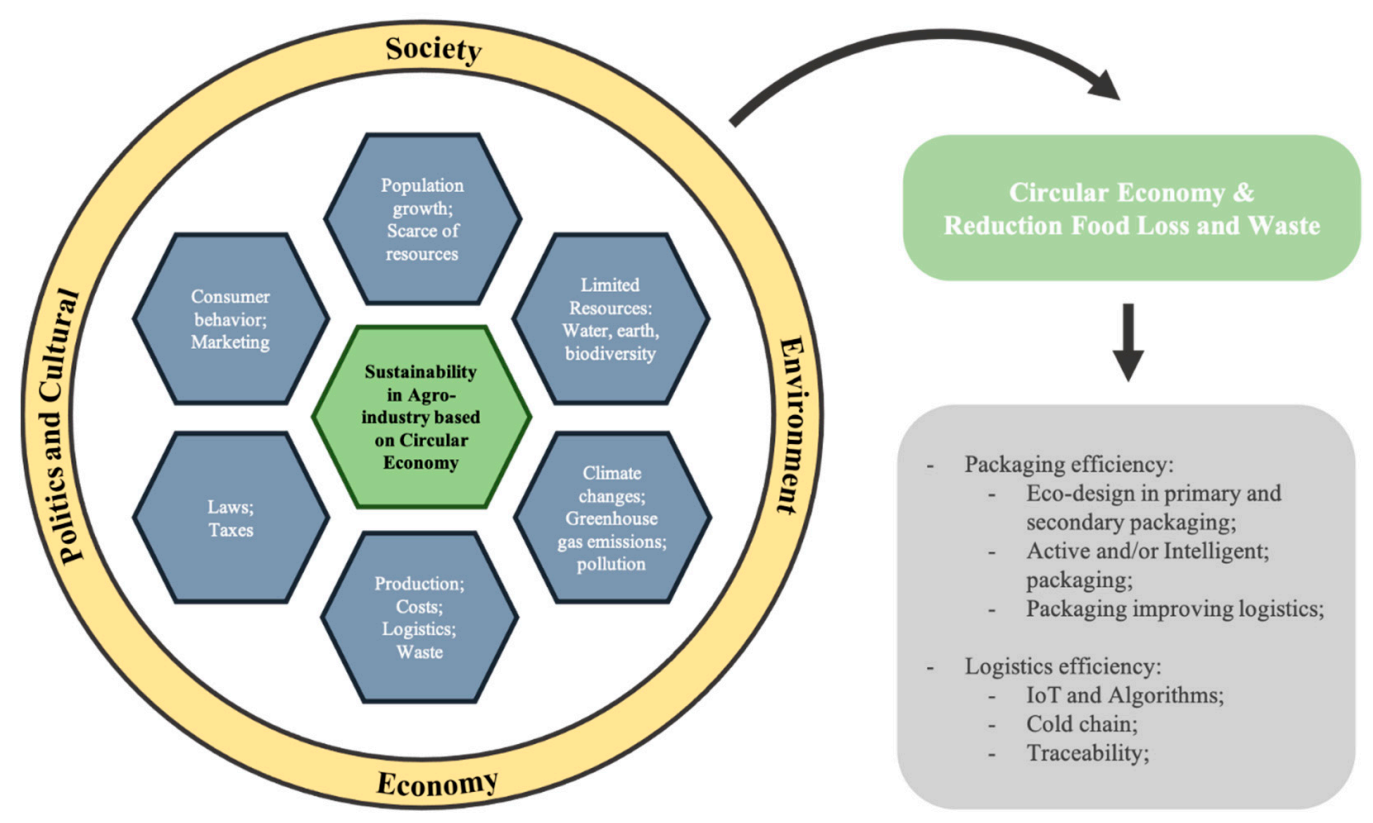

Figure 3. Diagram of sustainability in the agro-industry. Aiming at a circular economy and reduction of food loss, waste improving packaging and logistics efficiency (adapted from [34]).

The circular economy concept was developed as a tool to prevent and reduce harmful human assets, in order to drive global environmental change (Geueke et al., 2018). Thus, the circular economy is an economic model in which the planning, resources, acquisition, production and reprocessing are designed and generated, both as a process and as a product, to maximize the functioning of the ecosystem and human well-being [13].

Circular economy practices can also be advantageous in the use of bioenergy in the agro-industrial sector through influences on material flows and cost reduction [15]. Therefore, it is urgent to change from a linear approach "take-make-use-dispose" where resources highly dependent on fossil fuels are used for a circular approach focused on the continuous reuse of materials that are economically viable, and to use renewable resources when possible [13].

Practical and efficient solutions include eco-design in primary and secondary packaging [35], eco-design of products and processes, waste prevention programs and product life extension by intelligent and active packaging [36]. For application in modernized food packaging in the food industry, it is necessary to take into account several important points: cost, commercialization, consumer acceptance, food and environmental safety and food quality [37]. In addition, consumer education on the benefits of packaging technologies is recommended [24]. It is a growing concern that packaging materials have a direct impact on energy use and, consequently, on logistics and waste production as for example the packaging weight and volume that influence the energy used for transportation besides the higher amount of packaging waste [2]. Further research on new packaging production from renewable sources or recycled materials is needed [38], in order to improve distribution and logistics processes with new and more effective tools.

Many benefits were brought with the growing digitalization of the world's industry, in the FSC as well. New technologies can be applied to solve old paradigms and mitigate inefficiencies. Nowadays, Industry 4.0, based on data communication, mostly focusing on IoT, promises a revolution on the way that people and companies face the world.

The fourth industrial revolution received the name Industry 4.0 and originated in Germany in the 2010 with a focus on the total automation of production processes, which is possible through the development of cyber-physical systems, fundamentally based on cloud computing and in the development of the concept of IoT. It is projected to be the basis of future manufacturing processes and is considered one of the main facilitators of 
Industry 4.0, allowing the transition between traditional manufacturing systems to more modern ones, with fully automated processes, of better quality and efficiency [39,40].

It is aimed to be applied to supply chain operations, making it more efficient and effective in regards to logistics, reducing FLW, costs and carbon/energy footprint. IoT also allows for product traceability, location services, shelf-life conservation, inventory management, market intelligence, dynamic logistics, monitoring and control, improvement in cold chain, as well as better planning and co-ordination among the different stages of the supply chain. Automated coordination in real-time, considering remaining shelf life and supply and demand of fresh food will change the scenario of FLW [1].

However, according to Mourtzis et al. [41], despite all the advantages that many executives believe that IoT provides, such as a significant increase in competitive advantage, many companies still have a very limited adoption of these technologies, either by the investment required or the need for qualified technicians and professionals. Additionally, it brings renewed concerns about cybersecurity, which need to be minimized [1]. Another approach to improve the sustainability of the agro-industrial sector through logistics strategies is to promote short logistics circuits and to approach the producer from the retailer and from the consumer. These short circuits should be maximized in order to reduce food loss and waste, to reduce emissions of harmful gases to the environmental from transportation vehicles, and increase the freshness of perishable food products delivered to consumers.

\section{Challenges in Cybersecurity}

In logistics and supply chain sectors, movement, storage, and distribution of goods are based on data management, which leads to a concern in cybersecurity that is becoming a huge challenge in companies [42]. The Industry 4.0 and the extensive industry digitalization bring out enormous gains, leading to a very fast development using IoT as base for devices and systems linking physical and virtual objects capable of communicating with each other. This technology can be used to increase the efficiency in cities, in the agro-food supply chain, in the industry in general, for retailers, improve logistics, among others [10,43]. Thus, it turns regular Agriculture into Agriculture 4.0, where the data digitalization is present in the food and agriculture supply chain, and that is also supported by artificial intelligence, IoT, and automation, where farms, machines, and factories are connected in a network and are able to work together to optimize the food production according to the food consumption [44].

Despite significant gains, the general agro-industry is still far from Agriculture 4.0. However, it is very important, due to interconnectivity, to have concerns about security. This importance is reflected in the governments agenda, as the IoT Cybersecurity Improvement Act, from the US in 2020 and European Telecommunications Standards Institute (ETSI) introduced ETSI EN 303 645, which "establishes a security baseline for internet-connected consumer products and provides a basis for future IoT certification schemes" [45].

The digitalization increases lead to an increased risk. The elimination or mitigation of cyber risk and vulnerability can be achieved by enhancing cybersecurity inside the organizations. There are different definitions of cybersecurity depending on the stakeholders. According to the European Union Agency for Network and Information Security (ENISA) "Cybersecurity shall refer to security of cyberspace, where cyberspace itself refers to the set of links and relationships between objects that are accessible through a generalized telecommunications network, and to the set of objects themselves where they present interfaces allowing their remote control, remote access to data, or their participation in control actions within that Cyberspace" [46]. According to the International Telecommunication Union (ITU), cybersecurity is defined as "The collection of tools, policies, security concepts, security safeguards, guidelines, risk management approaches, actions, training, best practices, assurance and technologies that can be used to protect the cyber environment and organization and user's assets" [46]. In both definitions it is emphasized the importance 
of expanding cybersecurity not only in cyberspace but also in cyber-physical assets or the objects itself, which is directly related to IoT devices.

To formulate appropriate risk mitigations strategies, it is important to understand the cybersecurity risks and threats landscape, in order to classify, detect, analyze, privacy and protect, as described in Table 2 [45].

Table 2. Examples of working in progress for cybersecurity [45].

\begin{tabular}{cc}
\hline Field & Work in Progress (Cybersecurity) \\
\hline Classify & "Attacks on the Industrial Internet of Things-Development of a multi-layer Taxonomy" \\
Detect & "A novel approach for detecting vulnerable IoT devices connected behind a home NAT" \\
Analyze & "An Efficient and Privacy-Preserving Truth Discovery Scheme in Crowdsensing Applications" \\
Privacy & "Analyzing IOT users' mobile device privacy concerns: Extracting privacy permissions using a \\
Protect & "Extending Critical Infrastructure Element Longevity Using Constellation-Based ID Verification" \\
\hline
\end{tabular}

All stakeholders in FSC must collaborate with each other not only in business, but also in defense, sharing information to maintain supply chain network availability, connectivity, and security. Inside the organizations, insufficient cybersecurity awareness and lack of skilled cybersecurity staff can reduce the security and increase risks. Although cybersecurity is the backbone of Industry 4.0 and Agriculture 4.0, real cybersecurity data is still needed [42]. In particular, attacks against cyber-physical devices has been a work in progress not only for governments but also for researchers [45].

\section{Packaging}

The food packaging area is growing exponentially in the scientific and industrial sectors. It is an essential component in the FSC and is becoming a central process element in the food industries. This is due to the world population increase and compliance with new strict food safety regulations [37,47].

Packaging is defined as a science and technology that aims to ensure the quality, integrity, and safety of a product, including its technical-commercial functions [48]. It is also a coordinated system of preparation, preservation, and maintenance of quality for the transport, distribution, storage, sale and final consumption of products [37]. Food packaging plays a fundamental role in society and acts as an effective protective barrier. Thus, it protects food from possible physical damage and degradation, environmental contamination and other external factors in order to ensure the product quality, safety and hygiene during its useful life $[47,49]$. Food packaging is essential to minimize food waste [35].

Although packaging protects food by extending its useful life, it is often seen as having a negative impact on the environment, since after product consumption, the customer discards it [24]. In addition, this impact is also due to its high volume of production in a frequent short period of time and fast use, and problems related to waste management [35]. It is estimated that $41 \%$ of the packaging used in 2007 was for food and was mostly composed by plastic [3]. Other studies revealed the use of 1130 billion packages in the EU in 2018 [49]. This high consumption of packaging has resulted in a large production of waste: data indicate the generation of $156.9 \mathrm{~kg}$ of packaging waste per EU inhabitant in 2013. Moreover, it is estimated that packaging waste will increase at an annual rate of $4.2 \%$ in the coming years [49].

\subsection{Primary Packaging}

The suitable food packaging application can help to reduce and prevent the food waste generation. Thus, the proper selection of packaging must ensure that there are no negative changes in the quality of food, as well as the microorganism development or the nutrient degradation [47]. However, conventional packaging is usually disposable items that are eliminated when they reach the consumer or after using their content [47]. The main materials used in conventional food packaging are plastics, non-biodegradable, 
and with several limitations in their recycling. They represent $90 \%$ of the total plastic production [49]. In addition, one of the main problems is the unsustainable nature of plastics, because most of them are not renewable and neither biodegradable, with landfills and oceans as their main destination. Therefore, they represent a huge environmental burden [47]. With the growing environmental concern and the rate of packaging material waste, there is an increasing demand for food packaging that does not increase this environmental problem, and, in the other hand, food packaging manufactured efficiently by sustainable processes [47].

Biodegradable and edible packaging materials are considered one of the priorities of the food industry due to the need for alternative, renewable, recyclable and easily degradable packaging materials with special focus on the minimum or neither need for disposal. Biodegradable and bio-based polymers from natural resources are a potential raw material for developing food packaging materials, such as the poly (lactic acid) (PLA), polyhydroxyalkanoates (PHAs), chitosan, and diverse proteins obtained from animals and vegetables origin [50].

Bio-based and biodegradable substrates can be categorized according to their origin: materials developed from natural sources or direct biomass such as proteins, polysaccharides and lipids; materials developed by microorganisms or genetically-modified microorganisms, such as PHA polysaccharides; and materials produced from bio-based monomers, such as PLA [47].

Biopolymers can also be applied as edible materials as an alternative to traditional food packaging from the point of view of their film-forming properties and coatings. There exists a huge variety of edible bio-based polymers according to their nature and origin such as the chitosan coating, tomato-based, apple-based and cactus-mucilage edible films, and banana starch, among others [47].

On the other hand, nanotechnological applications in packaging are increasingly being seen, namely nanofillers. Different films produced with nanofillers have wide applications in coatings and food packaging. These provide impermeability to humidity, gases such as oxygen, carbon dioxide and also have good antibacterial properties, allowing to extend the food product's life. Nanocellulose (NC), prepared by breaking down cellulose fibers, is one of the most studied renewable and biodegradable nanofillers that produces a low carbon footprint. In addition to the chemical barrier properties, NC obtained from renewable resources is a green material and substrate for sustainable biodegradable packaging. NC is non-toxic and renewable because it is reprocessable and recyclable, without drastically degrading its properties [50].

\subsection{Secondary Packaging}

Currently, it is not possible to fully recycle plastic packaging that is widely used in the food industry, neither are there viable commercialized alternatives that provide the same level of protection. Thus, sustainability is the motivation behind the plastics strategy with the aim of addressing the way plastics are designed, used, and recycled [13].

Plastic packaging has benefits regarding food safety and preservation, as it helps to reduce food waste, is lighter, which allows the reduction of transportation costs, and is cheaper, which introduces a direct economic benefit and has offered a good performance in extending product life. The disadvantages are the environmental concerns that they entail, namely due to their high volume of production and their short time of use, often for a single use. In addition, the vast majority are not recyclable, given the enormous complexity of the recycling process resulting from the difficulty in separating polymeric mixtures [13].

One of the strategies outlined is that, by 2030, all plastic packaging placed on the EU market will be reusable or can be economically recyclable. To achieve this objective, it is necessary to adopt circular economy strategies. The main challenge of the circular economy is to close the material cycle and, in addition, keep it as small as possible in order to retain the qualities of the materials necessary to fulfill its original function. Plastic recycling is an 
essential part of the circular economy as less than $25 \%$ of collected plastic is recycled and about $50 \%$ goes to landfills [13].

Packaging is the main user of virgin materials and it is possible to reduce its need by reusing products and materials and thus closing the material cycles in a more sustainable way. Response strategies to reduce the volume and impact of the use of materials have focused on recycling, however, reusable packaging is recognized as a more efficient option in reducing the impact of the volume of packaging materials and energy used, avoiding an excessive production [28]. Thus, logistics strategies must be improved and developed to accomplish this objective. The application of traceability systems [51], supported by different data communication technologies, will promote these new approaches to promote reusability while optimizing logistics, reducing transport costs, and the environmental impact associated with transport within pooling systems.

\subsection{Intelligent and/or Active Packaging}

The information contained in packaging emerges as a solution to minimize FLW in the FSC. However, it generates drawbacks, which has become a huge problem and is important to deal with it [49]. The most common packaging functions are to be a barrier to protect the product against environment contamination, physical damage, correct product identification in the FSC, presenting details such as nutritional facts, health benefits, how to use and store, place of manufacture, date of manufacturing, expiry date, acts as a marketing tool for consumers, extend shelf life, and food safety. However, due to the side effects of packaging in the environment, is mandatory to be even more efficient to extend the product's shelf life, but also maintain the food's original physical and organoleptic properties $[43,48]$. This improvement can be achieved by using the most recent technologies to improve shelf life, namely intelligent packaging (IP) and active packaging (AP) or both in simultaneous [37], and points to a possible solution to mitigate FLW in the agro-industrial sector [26].

\subsubsection{Intelligent Packaging}

The concept of intelligent packaging, or also called smart packaging, has been forged by food packaging segment, clusters, and by research. Intelligent packaging is defined as "a control system inside packaging which is able to perform intelligent functions such as standby, detection, tracking, recording, and communicating in order to provide individual links in the packaging chain, i.e., producers, distributors, and sales representatives and consumers, with certain parameters" [52]. This packaging is able to provide data not just about the product's regular information such as origin, validity date, and organization, among others. It may additionally have the capacity to inform and/or advice producers, retailers or consumers about the historical data of the product, such as stockpiling conditions, headspace synthesis, extrinsic (e.g., temperature, humidity and atmosphere) and intrinsic (e.g., $\mathrm{pH}$ and water activity) parameters, and microbial development, among others [53].

Intelligent packaging can provide information concerning food quality, safety and the history of a product during transport and storage, through the six main functions of intelligent packaging: monitoring, detecting, sensing, recording, tracking, and communicating [54].

In summary, intelligent packaging is a package that is not only used to contain, protect, and extend the shelf life, but also, that is able to interact with the environment in realtime, delivering more information than regular packaging. Such information is related to the contained product, allowing to know precisely which is its real condition, safety, quality, location, or temperature, aiming to increase efficiency and reducing the FLW in all FSC. It is classified into three main groups, namely indicators, sensors, and data carriers. A schematic diagram shown in Figure 4 was elaborated to illustrate the main groups of Intelligent Packaging [48,55]. 


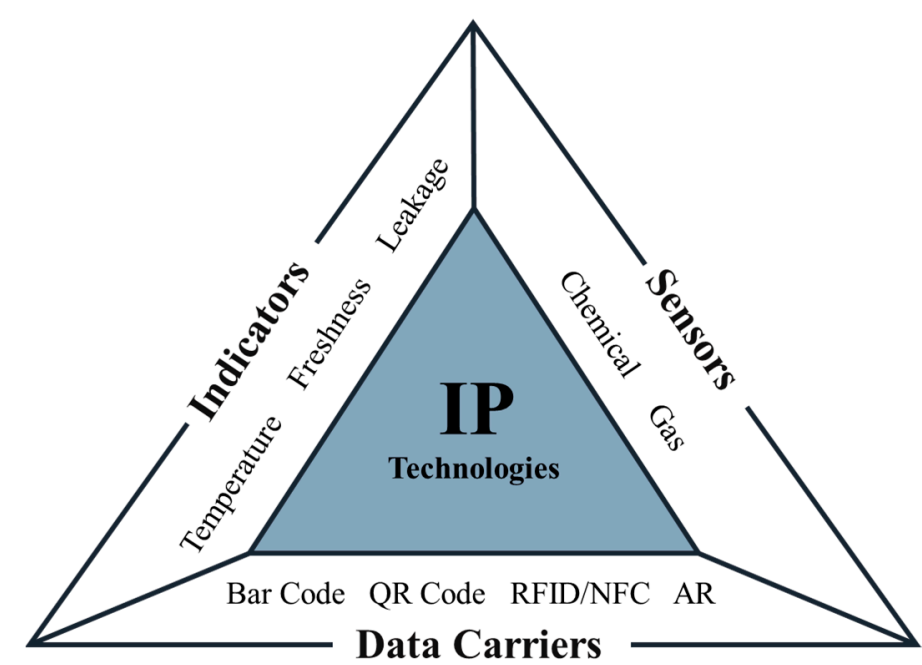

Figure 4. Main groups of Intelligent Packaging Technologies.

Indicators are devices that can determine the presence or absence and extent of reaction between two or more substances or the concentration of a particular substance. This information is transmitted for the user through irreversible and visible color change or movement of color frontiers. According to the application, it could be placed inside or outside of the packaging $[31,48,55]$. Sensors are electronic devices that can detect, quantify, and convert a signal to an electrical signal using transducers. Most sensors are composed of two parts. First is a sensor part, which can detect the presence, activity, composition, or concentration of certain chemical or physical analytes, such as $\mathrm{pH}$, humidity, color, and biological compounds. The physical or chemical information is also converted by the sensor into a form of energy that can be measured by the second component, the transducer $[55,56]$. Data carriers are the technique or device responsible for product identification [57]. This information allows traceability, following the movement of food products through a specified stage of production, processing, and distribution, helping to improve the food safety [48,56]. The most common data carriers are barcode labels, adopted for identification in the packaging industry, with limited information storage capability. In general, there are two types of barcodes, one-dimensional (1D) or two-dimensional (2D), the last one known as the quick response barcode (QR Code). The one-dimensional barcode is the most used in industry, as it is the simplest one and the cheapest. It is based on a pattern of parallel spaces and bars, where a different arrangement of the bars and gaps can result in a coding data. Two-dimensional barcodes have more storage capacity, and can contain information about packaging date, batch number, packaging weight, nutritional information, preparation instructions, or link to a website, allowing for much more information, and/or link to an Augmented Reality (AR) application. In both cases, an associated scanner is necessary. The radio frequency identification (RFID) tags emerge to increase the amount and the ability of exchange data of a product, and also allows for tracking and tracing inventory from production, logistics, to warehouse. There are three different arrangements possible, combining RFID and sensors, active, semi-passive and passive. Active tags can be easily coupled with sensors and work in real-time but must be powered by batteries. Semi-passive can be compared to an active tag. Nevertheless, it is only activated when is required to function, and does not allow for real-time applications. The passive is the cheaper one, where the tag is powered by an external electromagnetic field inducted by RFID readers. However, it cannot support complicated sensors. RFID readers are necessary to communicate with devices. The near-field communication (NFC) works in a similar way to RIFD, however, its range is only up to $4 \mathrm{~cm}$. It needs a NFC reader and is commonly used by consumers using its personal devices as readers too [56,57].

Intelligent packaging can bring out great advantages in all the FSC to reduce FLW, such as traceability, information about producer, shelf life, expiration date, freshness, 
temperatures, leaks, chemical alterations, among other information. However, the prices of the most recent technologies are still high, compared to traditional ones such as a bar code that is already widely used in the packaging industry. In addition, sensors and indicators which work in direct contact with the food create concerns about food safety.

\subsubsection{Active Packaging}

Changes in customers' lifestyles have increased the demand for clean, high-quality, fresh, ready-to-eat products with an extended shelf life, the appearance of new products on the market, the need for consumers to monitor their quality until consumption, and also reduce food corruption during the preservation time, which creates the urgency and need for modernized packaging technologies [37].

The concept of active packaging (AP) is characterized as a technology to increase the safety, quality and shelf life of packaged foods [58,59]. AP systems change the environmental conditions of packaged foods during the preservation period, but it is also necessary to preserve the safety, sensory properties and quality of packaged foods [37]. The AP reacts to different stimulations from food or the environment to allow monitoring or maintain food quality and safety in real time. Thus, AP systems can contribute to the reduction of food waste, providing an inert barrier to external conditions, functions associated with food preservation, removal of properties, microbiological control, and quality control. AP usually contain active agents for food packaging and are classified according to the active functions: microbial activity, antioxidant activity, oxygen and ethylene elimination, and carbon dioxide emission [58]. Figure 5 was designed to show the main functions applied in active packaging. The ethylene scavengers are systems specialized for ethylene elimination because this small volatile molecule acts as a phytohormone in the ripening and senescence of fruits and vegetables phenomenon. Oxygen scavengers ( $\mathrm{or}_{2}$ scavengers) are also capture systems, but, in this case, in a wide range of food products (e.g., cold meat and snacks) that are highly sensitive to oxygen, oxygen scavengers prevent the growth of aerobic microorganisms or oxidation of the product and consequently, eliminate the negative influence in quality and shelf-life of the packaged foods. Antioxidant active agents are gaining interest in food packaging due to their oxidative-stability ability. They protect food from oxidative degradation, which is responsible for food spoilage and consequently nutritional value decrease, off-flavors, and odor production and color change. $\mathrm{CO}_{2}$ emitters are carbon dioxide releasing systems for the quality preservation and shelf-life extension of products, namely meat and fish. Carbon dioxide interacts with food, resulting in carbonic acid formation and, thus, acidification of food products that leads to $\mathrm{pH}$ changes, alteration of bacterial cell membrane and inhibition of bacterial enzymes. Antimicrobial agents act directly in the growth of pathogenic microorganisms that are the major cause of food spoilage. Thus, antimicrobial components are one of the active agents that are the most studied, such as metal ions and oxides, essential oils, plant extracts, polysaccharides and peptides, bioactive components, enzymes, and synthetic compounds [58].

There are important issues associated with active packaging such as high cost, commercialization, low consumer acceptance, food and environmental safety, and organoleptic quality [37]. Furthermore, the interaction between the AP, the environment, and food are the main challenge for commercial transition. The use of active systems must comply with the requirements of different regulatory agencies, such as the Food and Drug Administration (FDA) and the European Food Safety Authority (EFSA), among other agencies that establish the legal basis for its precise use, security, and marketing [58]. 


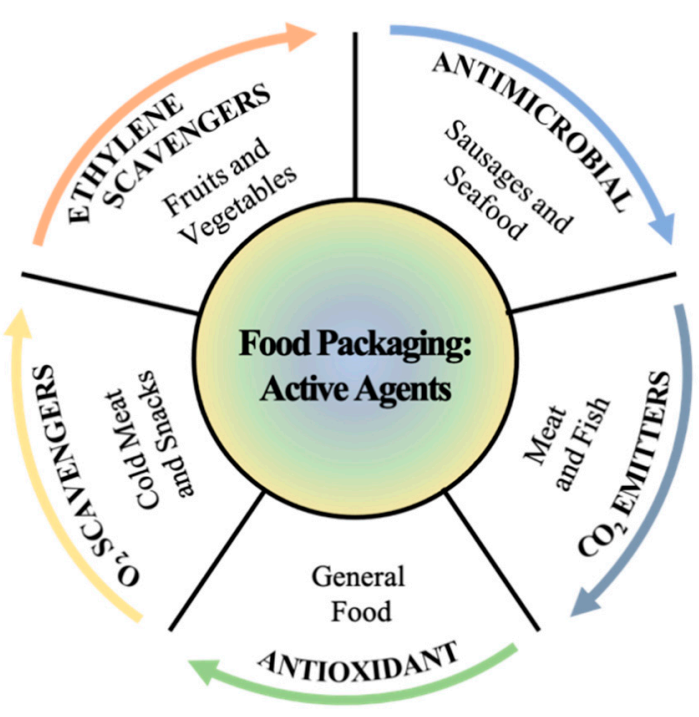

Figure 5. Active and functional agents for active food packaging.

\section{Conclusions}

The growth of population-associated consumption patterns is leading us into an unsustainable world-a "disposable society" with a dominant economic model based on "take, make and disposal". The material footprint to satisfy the essential needs of people, such as food, clothing, water, shelter, infrastructure, and other aspects of life increased by $17.4 \%$ between 2010 and 2017. Meanwhile, the recycling process is very much slower than the waste production, generating an unbalance according to the circular economy approach. This excessive material, which is incorrectly treated, commonly finds its final disposal in landfills and oceans. Imperative action is necessary to decrease mankind's reliance on raw materials and to change to a circular economy approach, aiming at "recycling, reuse, or recovery" to reduce environmental pressure and impact.

Many reasons can lead to FLW, such as customer behavior, laws, taxes, weather, and inefficiencies in all FSC. Best practices and a circular economy approach could mitigate FLW in all chain steps, although digitized and secure solutions in a circular economy approach are suggested, e.g., using residual food in the FSC. In addition, it is also important to use all parts of food, agro-industry losses, and wastes inclusive, even for different applications such as bio-fuel production, pigment production, agricultural composting, enzyme production and others, in such a manner that is possible to recover, at least in part a material which otherwise would be disposed.

The packaging has been adopted by agro-industry and many benefits are achieved, such as food product protection, extended shelf life, and information on all of FSC. However, best practices for ecological packaging are required, introducing the reuse and recycling systems, and also better controls and packaging improvements for sustainable efficiency. New systems such as intelligent and active packaging are a significant option as well for tracking and extending the shelf life of products even more in such a way that mitigates the packaging drawbacks, related to its disposal, once the technical issues regarding recycling and food safety concerns are solved. These improvements are related with eco-design to manufacture primary and secondary packages, making them more sustainable, and also, related to its function, to protect, inform, and extend the shelf life of food products.

Intelligent packaging enables a product to become a part of a system as a "thing" in IoT, where all the information is processed in real-time, allowing for better planning and decisions in all FSC. Indicators, sensors, and data carriers have different technologies, and its implementations are related to high costs and food safety and technology itself.

Active packaging functions are associated with food preservation, removal of properties, microbiological control, and quality control. However, there are important issues associated with active packaging such as high cost, commercialization, low consumer 
acceptance, food, and environmental safety. The use of innovative systems (intelligent and active packaging) must comply with the requirements of different regulatory agencies, such as the Food and Drug Administration and the European Food Safety Authority, among others regulatory agencies. Nevertheless, the cost of these technologies is becoming smaller as days go by, and its massification will certainly help in this sense.

Logistics also can benefit from digitalization, Industry 4.0, IoT, and intelligent and/or active packaging. Allowing traceability of the product, location services, shelf-life conservation, inventory management, market intelligence, dynamic logistics, monitoring and control, improvement in cold chain, as well as better planning and coordination among the different stages of the supply chain. Automated coordination in real-time, considering remaining shelf life, supply and demand of fresh food can change the scenario of FLW. Data digitalization can be present in food and agriculture systems, and is also supported by artificial intelligence, IoT, and automation, where farms, machines and factories are connected in a network and are able work together to optimize the food production according to the food consumption. It renews concerns about privacy and cybersecurity.

In FSC all stakeholders must collaborate with each other not only in business, but also in defense, sharing information to maintain supply chain network availability, connectivity, and security. Unfortunately, in the cybersecurity sector, there is a lack of real data, in particular, of attacks against cyber-physical devices, in such a way it has been a work in progress not only for governments, but also for researchers.

In summary, food loss and waste are identified as one of the main challenges in the agro-industrial sector. It is a very complex topic, so a discussion in the different stages of the food supply chain and different causes in each stage was carried out. As a result of the research, a large number of publications point to the trend of adopting packaging to reduce FLW, namely ecological, intelligent, and active packaging. In general, the application of these new technologies brings enormous advantages, both from a sustainability point of view, but also from an economic point of view, through the reduction of food loss and waste. However, one of the main barriers to the adoption of such technologies is related to the low awareness of the benefits that can be achieved. This lack of knowledge is current, especially in micro, small, and medium-sized companies in the agro-industrial segment. In addition, a circular economy must be applied to the agro-industrial sector to mitigate food waste and to be more eco-efficient. Further, materials that are already in use should be even more optimized with respect to its function, reuse, recycle, and recovery, by considering part of any material or its energy for production that will be lost along the FSC, which includes, soil, water, electricity, edible and inedible food and its loss and waste, packaging, logistics, and anything associated to the FSC that can further the sustainability of the process. Further, the continuous increase of the global awareness and qualification of agro-industrial MSMEs to adopt innovative and sustainable solutions, will foster their productivity, effectiveness, and efficiency in terms of Industry 4.0, the circular economy, and sustainability.

Author Contributions: Conceptualization, P.D.G.; methodology, P.D.G.; validation, P.D.G.; formal analysis, P.D.G.; investigation, C.M.F., J.A., P.D.G. and T.M.L.; writing-original draft preparation, C.M.F. and J.A.; writing - review and editing, P.D.G. and T.M.L.; supervision, P.D.G.; project administration, P.D.G.; funding acquisition, P.D.G. All authors have read and agreed to the published version of the manuscript.

Funding: This study is within the activities of project S4Agro-Soluções Sustentáveis para o Setor Agroindustrial (Sustainable Solutions for the Agro-industrial sector) promoted by COMPETE 2020POCI-SIAC: 02/SIAC/2019 (POCI-02-0853-FEDER-046425) and co-financed by FEDER under the Portugal 2020 initiative.

Institutional Review Board Statement: Not applicable.

Informed Consent Statement: Not applicable. 
Acknowledgments: The authors also acknowledge Fundação para a Ciência e a Tecnologia (FCTMCTES) for its financial support via the project UIDB/00151/2020 (C-MAST).

Conflicts of Interest: The authors declare no conflict of interest.

\section{References}

1. Villalobos, J.R.; Soto-Silva, W.E.; González-Araya, M.C.; González-Ramirez, R.G. Research directions in technology development to support real-time decisions of fresh produce logistics: A review and research agenda. Comput. Electron. Agric. 2019, 167, 105092. [CrossRef]

2. Escursell, S.; Llorach-Massana, P.; Roncero, M.B. Sustainability in e-commerce packaging: A review. J. Clean. Prod. 2021, 280, 1-17. [CrossRef]

3. Kakadellis, S.; Harris, Z.M. Don't scrap the waste: The need for broader system boundaries in bioplastic food packaging life-cycle assessment-A critical review. J. Clean. Prod. 2020, 274, 1-14. [CrossRef]

4. Ghisellini, P.; Cialani, C.; Ulgiati, S. A review on circular economy: The expected transition to a balanced interplay of environmental and economic systems. J. Clean. Prod. 2016, 114, 11-32. [CrossRef]

5. United Nations. The Sustainable Development Goals Report 2020; Department of Economic and Social Affairs: New York, NY, USA, 2020.

6. WCED. Our common future. In United Nations General Assembly Document A/42/427; Brundtland, G.H., Ed.; Oxford University Press: Oxford, UK, 1987.

7. Ghobakhloo, M. Industry 4.0, digitization, and opportunities for sustainability. J. Clean. Prod. 2020, 252, 1-21. [CrossRef]

8. Huang, I.Y.; Manning, L.; James, K.L.; Grigoriadis, V.; Millington, A.; Wood, V.; Ward, S. Food waste management: A review of retailers' business practices and their implications for sustainable value. J. Clean. Prod. 2021, 285, 1-15. [CrossRef]

9. Caldeira, C.; De Laurentiis, V.; Corrado, S.; Van Holsteijn, F.; Sala, S. Quantification of food waste per product group along the food supply chain in the European Union: A mass flow analysis. Resour. Conserv. Recycl. 2019, 149, 479-488. [CrossRef]

10. Osorio, L.L.D.R.; Flórez-López, E.; Grande-Tovar, C.D. molecules The Potential of Selected Agri-Food Loss and Waste to Contribute to a Circular Economy: Applications in the Food, Cosmetic and Pharmaceutical Industries. Molecules 2021, $26,515$. [CrossRef]

11. Kee, S.H.; Chiongson, J.B.V.; Saludes, J.P.; Vigneswari, S.; Ramakrishna, S.; Bhubalan, K. Bioconversion of agro-industry sourced biowaste into biomaterials via microbial factories-A viable domain of circular economy. Environ. Pollut. 2021, $271,1-15$. [CrossRef]

12. Santagata, R.; Ripa, M.; Genovese, A.; Ulgiati, S. Food waste recovery pathways: Challenges and opportunities for an emerging bio-based circular economy. A systematic review and an assessment. J. Clean. Prod. 2021, 286, 1-15. [CrossRef]

13. Matthews, C.; Moran, F.; Jaiswal, A.K. A review on European Union's strategy for plastics in a circular economy and its impact on food safety. J. Clean. Prod. 2021, 283, 1-13. [CrossRef]

14. European Comission 2030 Climate \& Energy Framework | Ação Climática. Available online: https://ec.europa.eu/clima / policies / strategies/2030_pt\#tab-0-0 (accessed on 24 February 2021).

15. Barros, M.V.; Salvador, R.; De Francisco, A.C.; Piekarski, C.M. Mapping of research lines on circular economy practices in agriculture: From waste to energy. Renew. Sustain. Energy Rev. 2020, 131, 1-12. [CrossRef]

16. Morais, D.; Silva, P.D.; Gaspar, P.D.; Pires, L.C.; Andrade, L.P. Characterization of refrigeration systems in the Portuguese food processing industry. In Proceedings of the 25th IIR International Congress of Refrigeration (ICR 2019), Montreal, QC, Canada, 24-30 August 2019.

17. Andrade, L.P.; Nunes, J.; Simões, M.P.; Morais, D.; Cannavarro, C.; Espírito Santo, C.; Gaspar, P.D.; Silva, P.D.; Resende, M.; Caseiro, C.; et al. Experimental study of the consequences of controlled atmosphere conservation environment on cherry characteristics. Refrig. Sci. Technol. 2019, 2019-August, 3059-3066. [CrossRef]

18. Rodrigues, C.; Gaspar, P.D.; Simões, M.P.; Silva, P.D.; Andrade, L.P. Review on techniques and treatments toward the mitigation of the chilling injury of peaches. J. Food Process. Preserv. 2020, 1-12. [CrossRef]

19. Morais, D.; Gaspar, P.D.; Silva, P.D.; Santos, F.C.; Andrade, L.P.; Nunes, J. Assessment of the energy consumption and technologies in the bakery and pastry sector-The Portuguese case study. Energy Procedia 2019, 161, 83-92. [CrossRef]

20. Morais, D.; Gaspar, P.D.; Silva, P.D.; Andrade, L.P.; Nunes, J. Energy consumption and efficiency measures in the Portuguese food processing industry. J. Food Process. Preserv. 2020, e14862. [CrossRef]

21. Aguiar, M.L.; Gaspar, P.D. Refrigerantes naturais: Tendências do mercado, políticas e tecnologias na indústria agroalimentar portuguesa. In Proceedings of the X Iberian Congress and VIII Ibero-American Congress of Cold Sciences and Techniques (CYTEF 2020), Navarra, Spain, 11-13 November 2020; pp. 323-330.

22. European Union. Monitoring Agri-trade Policy; European Commission: Brussel, Belgium, 2019.

23. Zeng, T.; Deschênes, J.; Durif, F. Eco-design packaging: An epistemological analysis and transformative research agenda. J. Clean. Prod. 2020, 276, 1-19. [CrossRef]

24. Brennan, L.; Langley, S.; Verghese, K.; Lockrey, S.; Ryder, M.; Francis, C.; Phan-Le, N.T.; Hill, A. The role of packaging in fighting food waste: A systematised review of consumer perceptions of packaging. J. Clean. Prod. 2021, 281, 1-42. [CrossRef]

25. Commission for Environmental Cooperation. Characterization and Management of Food Loss and Waste in North America; Commission for Environmental Cooperation: Montreal, QC, Canada, 2017. 
26. Spang, E.S.; Moreno, L.C.; Pace, S.A.; Achmon, Y.; Donis-Gonzalez, I.; Gosliner, W.A.; Jablonski-Sheffield, M.P.; Abdul Momin, M.; Quested, T.E.; Winans, K.S.; et al. Food Loss and Waste: Measurement, Drivers, and Solutions. Annu. Rev. Environ. Resour. 2019, 44, 112-156. [CrossRef]

27. Rai, P.; Mehrotra, S.; Priya, S.; Gnansounou, E.; Sharma, S.K. Recent advances in the sustainable design and applications of biodegradable polymers. Bioresour. Technol. 2021, 325, 124739. [CrossRef]

28. Coelho, P.M.; Corona, B.; Klooster, R.T.; Worrell, E. Sustainability of reusable packaging-Current situation and trends. Resour. Conserv. Recycl. X 2020, 6, 1-11. [CrossRef]

29. Haji, M.; Kerbache, L.; Muhammad, M.; Al-Ansari, T. Roles of Technology in Improving Perishable Food Supply Chains. Logistics 2020, 4, 33. [CrossRef]

30. Laso, J.; Campos, C.; Fernández-Ríos, A.; Hoehn, D.; Del Río, A.; Ruiz-salmón, I.; Cristobal, J.; Quiñones, A.; Amo-setién, F.J.; Ortego, M.; et al. Looking for answers to food loss and waste management in spain from a holistic nutritional and economic approach. Sustainability 2021, 13, 125. [CrossRef]

31. Morais, D.; Aguiar, M.L.; Gaspar, P.D.; Silva, P.D. Development of a Monitoring Device for Fruit Products Transportation in the Cold Chain. Procedia Environ. Sci. Eng. Manag. 2021, 8, 195-204.

32. Curto, J.; Gaspar, P.D. SME and quality focused traceability architecture to increase sustainability and profit. In Proceedings of the 6th IIR Conference on Sustainability and the Cold Chain (ICCC 2020), Nantes, France, 26-28 August 2020; pp. $428-435$.

33. Mendes, A.; Cruz, J.; Saraiva, T.; Lima, T.M.; Gaspar, P.D. Logistics strategy (FIFO, FEFO or LSFO) decision support system for perishable food products. In Proceedings of the 2020 International Conference on Decision Aid Sciences and Application (DASA), Zallaq, Bahrain, 8-9 November 2020; pp. 173-178.

34. Fernandes, A. Sustentabilidade na Agroindustria. Available online: https://pt.slideshare.net/acruzfe1962/sustentabilidade-naagroindustria (accessed on 23 February 2021).

35. Madhan, S.K.; Gaspar, P.D.; Silva, P.D.; Andrade, L.P.; Santo, C.E. A future trends of innovative green packaging of the food products to deplastification. In Proceedings of the 6th IIR International Conference on Sustainability and the Cold Chain (ICCC 2020), Nates, France, 26-28 August 2020; pp. 436-443.

36. Geueke, B.; Groh, K.; Muncke, J. Food packaging in the circular economy: Overview of chemical safety aspects for commonly used materials. J. Clean. Prod. 2018, 193, 491-505. [CrossRef]

37. Firouz, M.S.; Mohi-Alden, K.; Omid, M. A critical review on intelligent and active packaging in the food industry: Research and development. Food Res. Int. 2021, 141, 1-24. [CrossRef]

38. Kumar, S.; Leitão, F.; Gaspar, P.D.; Silva, P.D. Experimental Tests of the Thermal Behaviour of New Sustainable Bio-Packaging Food Boxes. Procedia Environ. Sci. Eng. Manag. 2021, 8, 215-223.

39. Thramboulidis, K.; Vachtsevanou, D.C.; Kontou, I. CPuS-IoT: A cyber-physical microservice and IoT-based framework for manufacturing assembly systems. Annu. Rev. Control. 2019, 47, 237-248. [CrossRef]

40. Ehie, I.C.; Chilton, M.A. Understanding the influence of IT/OT Convergence on the adoption of Internet of Things (IoT) in manufacturing organizations: An empirical investigation. Comput. Ind. 2020, 115, 1-11. [CrossRef]

41. Mourtzis, D.; Vlachou, E.; Milas, N. Industrial Big Data as a Result of IoT Adoption in Manufacturing. Procedia CIRP 2016, 55, 290-295. [CrossRef]

42. Cheung, K.F.; Bell, M.G.H.; Bhattacharjya, J. Cybersecurity in logistics and supply chain management: An overview and future research directions. Transp. Res. Part. E Logist. Transp. Rev. 2021, 146, 1-18. [CrossRef]

43. Saetta, S.; Caldarelli, V. How to increase the sustainability of the agri-food supply chain through innovations in 4.0 perspective: A first case study analysis. Procedia Manuf. 2020, 42, 333-336. [CrossRef]

44. Jambrak, A.R.; Nutrizio, M.; Djekić, I.; Pleslić, S.; Chemat, F. Internet of nonthermal food processing technologies (IoNTP): Food industry 4.0 and sustainability. Appl. Sci. 2021, 11, 686. [CrossRef]

45. Choo, K.K.R.; Gai, K.; Chiaraviglio, L.; Yang, Q. A multidisciplinary approach to Internet of Things (IoT) cybersecurity and risk management. Comput. Secur. 2021, 102, 1-3. [CrossRef]

46. ENISA. Definition of Cybersecurity_Gaps and Overlaps in Standardisation; ENISA: Athens, Greece, 2015.

47. Trajkovska Petkoska, A.; Daniloski, D.; D'Cunha, N.M.; Naumovski, N.; Broach, A.T. Edible packaging: Sustainable solutions and novel trends in food packaging. Food Res. Int. 2021, 140, 109981. [CrossRef]

48. Kalpana, S.; Priyadarshini, S.R.; Maria Leena, M.; Moses, J.A.; Anandharamakrishnan, C. Intelligent packaging: Trends and applications in food systems. Trends Food Sci. Technol. 2019, 93, 145-157. [CrossRef]

49. Cazón, P.; Vázquez, M. Bacterial cellulose as a biodegradable food packaging material: A review. Food Hydrocoll. 2021, 113, 1-9. [CrossRef]

50. Ahankari, S.S.; Subhedar, A.R.; Bhadauria, S.S.; Dufresne, A. Nanocellulose in food packaging: A review. Carbohydr. Polym. 2021, 255, 1-17. [CrossRef]

51. Morais, D.; Gaspar, P.D.; Silva, P.D.; Nunes, J.; Andrade, L.P.; Simões, M.P.; Pires, L.C. Current status and future trends of monitoring technologies for food products traceability. In Proceedings of the 25th IIR International Congress of Refrigeration (ICR 2019), Montreal, QC, Canada, 24-30 August 2019.

52. Barska, A.; Wyrwa, J. Innovations in the food packaging market—Intelligent packaging-A review. Czech J. Food Sci. 2017, 35, 1-6. [CrossRef]

53. Realini, C.E.; Marcos, B. Active and intelligent packaging systems for a modern society. Meat Sci. 2014, 98, 404-419. [CrossRef] 
54. Jang, N.Y.; Won, K. New pressure-activated compartmented oxygen indicator for intelligent food packaging. Int. J. Food Sci. Technol. 2014, 49, 650-654. [CrossRef]

55. Müller, P.; Schmid, M. Intelligent packaging in the food sector: A brief overview. Foods 2019, 8, 16. [CrossRef] [PubMed]

56. Gaspar, P.D.; Da Silva, P.D.; Andrade, L.P.; Nunes, J.; Santo, C.E. Technologies for Monitoring the Safety of Perishable Food Products. In Research Anthology on Food Waste Reduction and Alternative Diets for Food and Nutrition Security; IGI Global: Hershey, PA, USA, 2021; pp. 63-98.

57. Wang, L.; Wu, Z.; Cao, C. Technologies and fabrication of intelligent packaging for perishable products. Appl. Sci. 2019, 9, 4858. [CrossRef]

58. Vilela, C.; Kurek, M.; Hayouka, Z.; Röcker, B.; Yildirim, S.; Antunes, M.D.C.; Nilsen-Nygaard, J.; Pettersen, M.K.; Freire, C.S.R. A concise guide to active agents for active food packaging. Trends Food Sci. Technol. 2018, 80, 212-222. [CrossRef]

59. Madhan, S.; Santo, C.E.; Andrade, L.P.; Silva, P.D.; Gaspar, P.D. Active and Intelligent Packaging with Phase Change Materials to Promote the Shelf Life Extension of Food Products. KnE Eng. 2020, 5, 232-241. [CrossRef] 